\title{
Endosonographic diagnosis of choledochocele
}
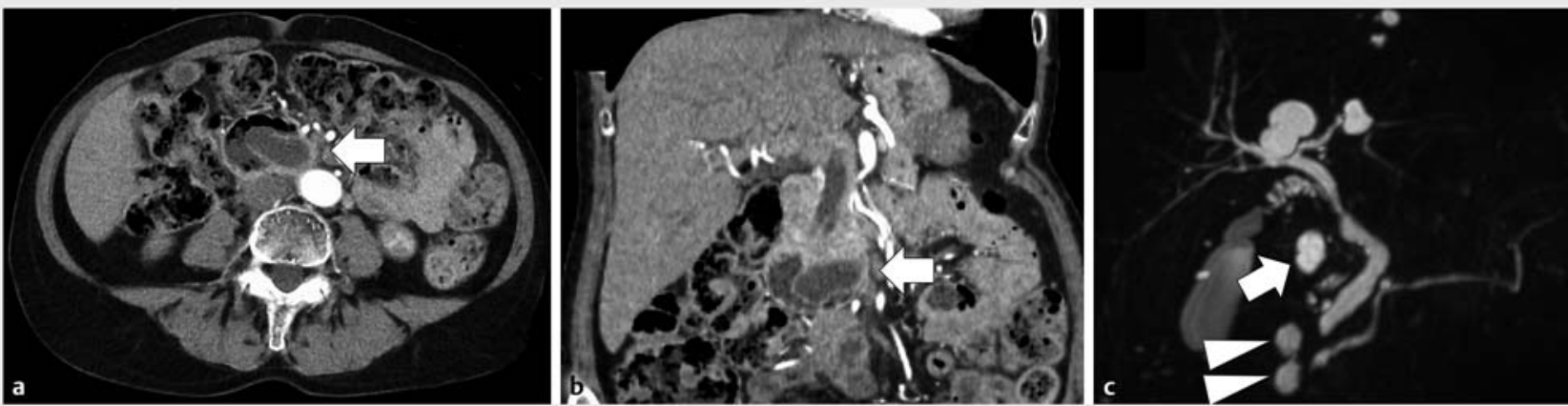

- Fig. 1 a Axial and b coronal views of computed tomography with contrast revealed a cyst-like, fluid-filled structure at the inferior duodenal angle (white arrows). No communication between the structure and the bile or pancreatic ducts was noted. c Magnetic resonance cholangiopancreatography revealed one cystic lesion at the superior duodenal angle (white arrow) and two cystic lesions at the inferior duodenal angle (white arrowheads). There appeared to be no communication between the two inferior duodenal angle lesions and the bile or pancreatic ducts. No anomalous pancreaticobiliary duct union, choledocholithiasis, or malignancy were noted.

Choledochal cysts are rare congenital cystic dilatations of the biliary tree. Almost $80 \%$ are discovered during childhood and they are most common in Asian women [1]. They are generally associated with anomalous pancreaticobiliary duct union and treated surgically because of the high risk of biliary malignancy.

Choledochoceles (Todani type III choledochal cysts) are intraduodenal cystic dilatations of the distal bile duct which make up $0.5 \%$ to $4 \%$ of choledochal cysts $[1,2]$. They are unique in that they exhibit even gender distribution and are only rarely associated with anomalous pancreaticobiliary duct union or malignancy. Endoscopic sphincterotomy, unroofing, or cyst resection, therefore, can be considered in lieu of surgery $[3,4]$.

A 69-year-old woman recovering from endovascular therapy for aortic dissection was referred for evaluation of suspected duodenal cysts. She had no abdominal symptoms or history of biliary stones, pancreatitis, or malignancy. Computed tomography (CT) with contrast revealed a fluid-filled cystic structure at the inferior duodenal angle and a mildly dilated bile duct with no visible obstructive lesions ( $>$ Fig.1a, $>$ Fig.1b).
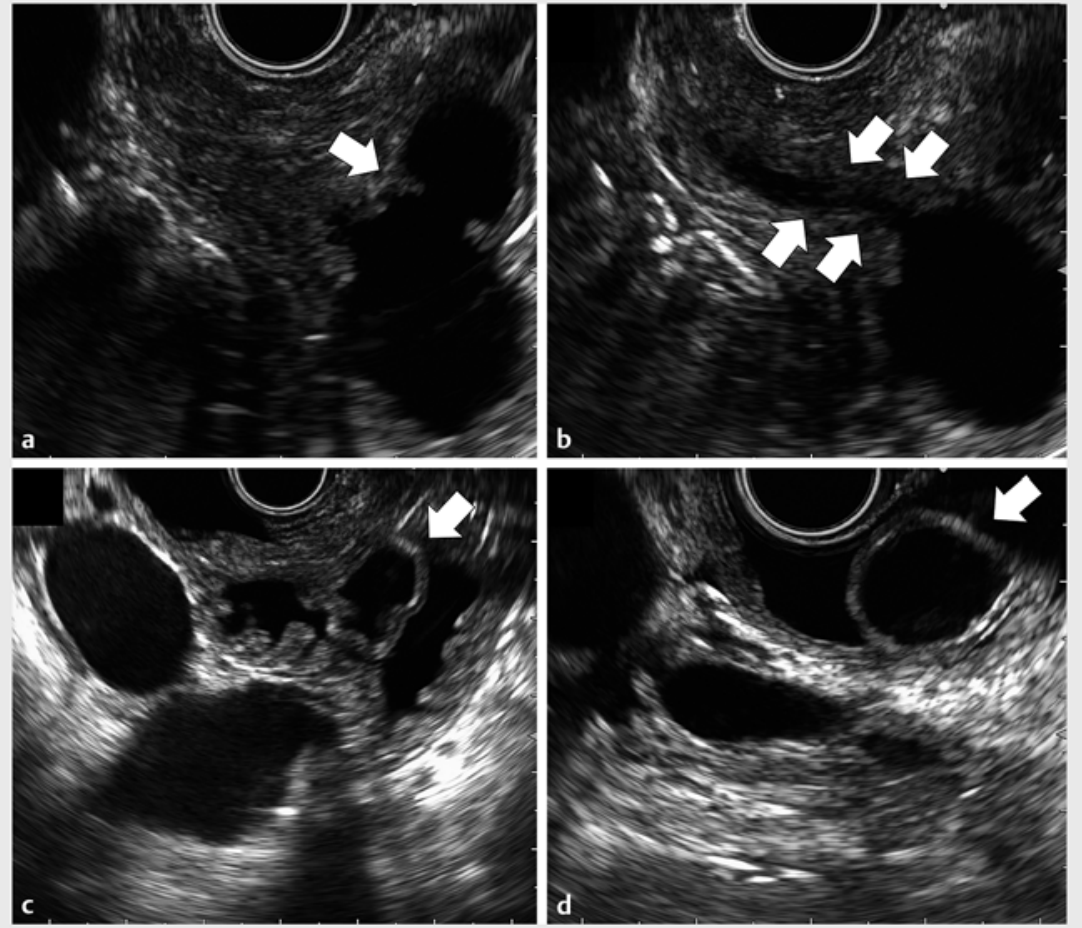

- Fig. 2 Endoscopic ultrasound (EUS) findings. a Communication between two cystic structures in the duodenum was observed (white arrow). b Communication between the two cystic structures and the distal bile duct was confirmed (white arrows). $\mathrm{c}$ When immersed in water, the cysts (white arrow) were soft and located in the duodenum, completely outside the pancreas. $\mathbf{d}$ A duodenal cyst at the superior duodenal angle (white arrow) was indistinguishable from the choledochocele on EUS, except for the communication with the bile duct. 


\section{Endosonographic diagnosis of chc is :ele}

Takeshi Okamoto and Katsuyuki Fukuda

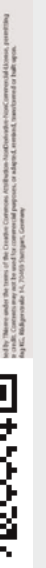

- Video 1 EUS revealed two cystic structures communicating with each other and the distal bile duct, leading to the diagnosis of choledochocele.

\section{References}

[1] Ronnekleiv-Kelly SM, Soares KC, Ejaz A et al. Management of choledochal cysts. Curr Opin Gastroenterol 2016; 32: 225-231

[2] Todani T, Watanabe Y, Narusue M et al. Congenital bile duct cysts: Classification, operative procedures, and review of thirtyseven cases including cancer arising from choledochal cyst. Am J Surg 1977; 134 : 263-269

[3] Lopez RR, Pinson CW, Campbell JR et al. Variation in management based on type of choledochal cyst. Am J Surg 1991; 161: 612-615

[4] Soares KC, Arnaoutakis DJ, Kamel I et al. Choledochal cysts: presentation, clinical differentiation, and management. J Am Coll Surg 2014; 219: 1167-1180

[5] Park DH, Kim MH, Lee SK et al. Can MRCP replace the diagnostic role of ERCP for patients with choledochal cysts? Gastrointest Endosc 2005; 62: 360-366

\section{Bibliography}

Endosc Int Open 2021; 09: E1579-E1580

DOI 10.1055/a-1526-1706

ISSN 2364-3722

(C) 2021. The Author(s).

This is an open access article published by Thieme under the terms of the Creative Commons Attribution-NonDerivativeNonCommercial License, permitting copying and reproduction so long as the original work is given appropriate credit. Contents may not be used for commercial purposes, or adapted, remixed, transformed or built upon. (https:// creativecommons.org/licenses/by-nc-nd/4.0/) Georg Thieme Verlag KG, Rüdigerstraße 14, 70469 Stuttgart, Germany

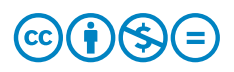

nication with the bile duct. The patient declined endoscopic treatment because she was asymptomatic and was recovering from aortic dissection.

Choledochal cysts are most often discovered on abdominal ultrasound and diagnosed with MRCP [1]. While CT and MRCP both have sensitivities and specificities of about $90 \%$, neither could demonstrate communication between the intraduodenal cysts and bile duct in this case $[1,4,5]$.

\section{Japanese Foundation for Cancer Research, Tokyo, Japan \\ 2 Department of Gastroenterology, St. Luke's International Hospital, Tokyo, Japan \\ Takeshi Okamoto $^{1,2}$, Katsuyuki Fukuda \\ 1 Department of Hepato-Biliary-Pancreatic}

\section{Corresponding author}

\section{Takeshi Okamoto, MD}

Department of Hepato-Biliary-Pancreatic Medicine, Cancer Institute Hospital of Japanese Foundation for Cancer Research, 38-31, Ariake, Koto, Tokyo, 135-8550, Japan Fax: +81-3-3520-0141

tak@afia.jp 